\title{
Design, Synthesis and Enhanced BBB Penetration Studies of L-serine-Tethered Nipecotic Acid-Prodrug
}

\author{
Authors \\ Meenakshi Dhanawat묘, Sumeet Gupta(D), Dinesh Kumar Mehta, Rina Das
}

Affiliation

MM College of Pharmacy, MM (Deemed to be University), Mullana, Ambala, Haryana

\section{Key words}

antiepileptic drugs, drug delivery, central nervous system disorders

received $\quad 14.08 .2020$

accepted $\quad 12.10 .2020$

published online $\quad 25.11 .2020$

\author{
Bibliography \\ Drug Res 2021; 71: 94-103 \\ DOI 10.1055/a-1290-0119 \\ ISSN 2194-9379
}

(c) 2020. Thieme. All rights reserved.

Georg Thieme Verlag KG, Rüdigerstraße 14,

70469 Stuttgart, Germany

\section{Correspondence}

Dr. Meenakshi Dhanawat

MM College of Pharmacy, MM (Deemed to be University),

Mullana, Ambala

Haryana

133207

India

Tel.: + 91 7726076397, fax: +91 01731304258

meenakshi.itbhu@gmail.com; mdanawat.rs.phe@itbhu.ac.in

\section{ABSTRACT}

Nipecotic acid is considered to be one of the most potent inhibitors of neuronal and glial-aminobutyric acid (GABA) uptake in vitro. Due to its hydrophilic nature, nipecotic acid does not readily cross the blood-brain barrier (BBB). Large neutral amino acids (LAT1)-knotted nipecotic acid prodrug was designed and synthesized with the aim to enhance the BBB permeation by the use of carrier-mediated transport. The synthesized prodrug was tested in animal models of Pentylenetetrazole (PTZ)-induced convulsions in mice. Further pain studies were carried out followed by neurotoxicity estimation by writhing and rotarod test respectively. HPLC data suggests that the synthesized prodrug has improved penetration through BBB. Nipecotic acid-L-serine ester prodrug with considerable anti-epileptic activity, and the ability to permeate the BBB has been successfully synthesized. - Graphical Abstract.

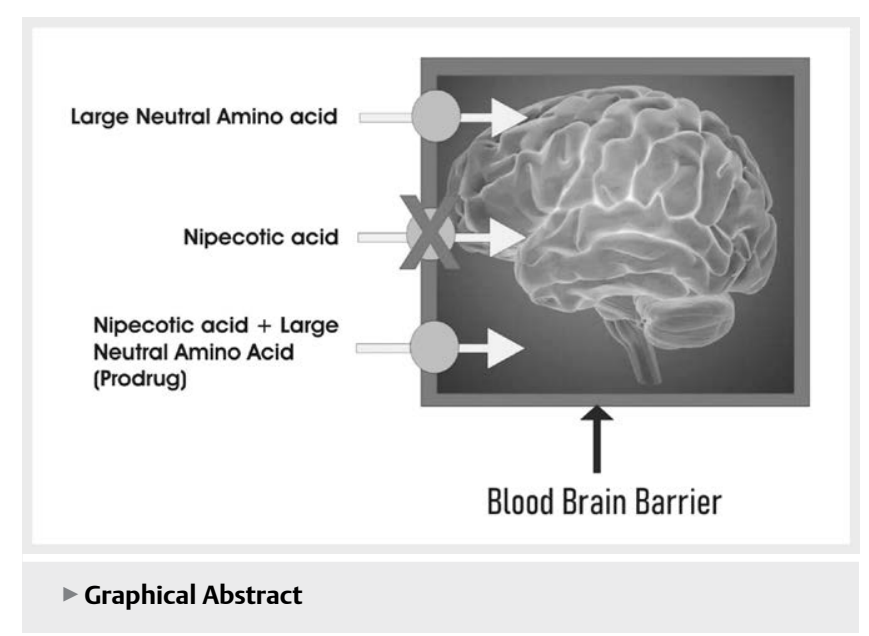

\section{Introduction}

Epilepsy is a neurological disorder with a focal origin in the brain and is characterized by paroxysmal cerebral dysrhythmia, recurrent seizures, and disturbance of consciousness [1,2]. It is one of the most common disorders of the central nervous system (CNS) affecting about 50000000 of the global population [3]. In a neurological disorder like epilepsy, a diminution in GABA-ergic neurotransmission is observed resulting in a decreased duration of inhibitory postsynaptic potentials. GABA transporters (GATs) are respon- sible for the transport of GABA to glial cells as well as presynaptic neurons, and thus terminate GABA-ergic neurotransmission [4].

A rational approach for enhancing GABA neurotransmission would be the blockade of GABA uptake system leading to the elevation of GABA concentration within the synaptic cleft [5]. Some of the compounds which are chemically active and potentially effective pharmacologically cannot cross the blood brain barrier without precursor. Nipecotic acid fails to cross the BBB owing to its polar and zwitterionic nature. The potential antiepileptic activity of nipecotic acid coupled with its synthetic versatility has led to the 
synthesis of a vast number of structurally diverse lipophilic derivatives with marked antiepileptic activity [6-13]. It has been found that substances crossing the BBB through many pathways (Transmembrane diffusion, Carrier mediated-transport and transcytosis). The use of transporters or precursors is one of the common pathway that is used to breech the BBB and among these trasporters L-type amino acid transporters (LAT1) have perhaps been most common ( Fig. 1) [13].

The most common amino acid with highest affinity for LAT1 is the phenylalanine, apart from this LAT1 also transports over 10 other large neutral amino acids [14] and to a lesser extent small neutral amino acids [15].

\section{Basic pharmacophoric requirement for LAT1 affinity}

In $>$ Fig. 1, the model of the binding site of the cerebrovascular LAT1 transporter has been shown ( $\vee$ Fig. 1). It is already proven that for a substrate to have affinity for LAT1, it must contain a) an unsubstituted, free carboxyl group, b) an unsubstituted $\alpha$-primary amino group, $c$ ) either a $\mathrm{H}$ or $\mathrm{CH}_{3}$ on the $\alpha$-carbon and d) a neutral, uncharged side chain with hydrophobic bulk.

\section{Design consideration}

LAT-1 is important because it transports several prescription drugs, such as the antiparkinsonian drug L-dopa and the anticonvulsant gabapentin, across the BBB, thereby enabling their pharmacologic effects $[10,11]$. This function at the BBB has made LAT-1 a target for drug delivery by modifying CNS-impermeable drugs such that they become LAT-1 substrates and have enhanced BBB penetration [12-15].

A vast number of structurally diverse lipophilic derivatives of nipecotic acid with marked antiepileptic activity like SKF 89976A $[6,8,16], \mathrm{NO}-328$ (now marketed as tiagabine) [10], Cl966 [11, 12] and $N$-(mono)- or $N$-(diaryl methoxy) alkyl derivatives [13] have been characterized as potent in vitro GABA uptake inhibitors along with demonstration of their antiepileptic activity in several in vivo rodent models ( $\triangleright$ Fig. 2 ).

It was well said that the identification of novel LAT1 substrates eg. gabapentine, paroxetine, clomipramine, leucine and duloxetine may focus on the mechanism through which drugs enter the brain,

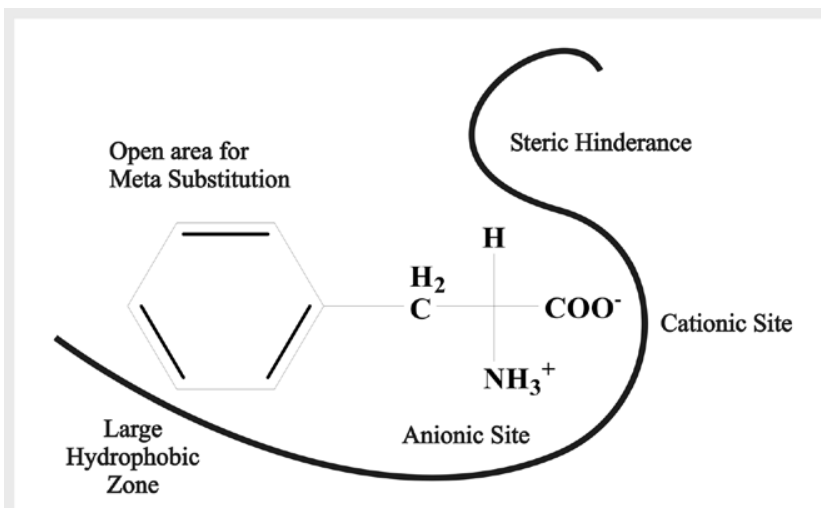

- Fig. 1 Basic Pharmacophore. this can actually enlighten the path to researchers for the development of novel therapeutics that can utilize LAT1 as a drug delivery platform ( $\triangleright$ Fig. 2).

A number of literatures are available which support the design of current nipecotic acid prodrug [13, 17-24].

On the basis of above concepts, we have arrived on the conclusion for the design of nipecotic acid-L-serine-conjugated amino acid ( $\triangleright$ Fig. 3)

\section{Experimental}

\section{Chemistry}

All the chemicals and solvents used for the synthesis were of analytical grade. Melting points were determined using open capillary tubes on a Stuart Melting Point apparatus (SMP10) and were uncorrected. The reaction progress was monitored by performing thin layer chromatography (TLC) on a precoated Merck silica gel 60F254 aluminum sheets (Merck, Germany). The visualization of TLC was done using UV cabinet ( $254 \mathrm{~nm}$ ) or iodine vapors. IR spectroscopy was performed using FT-IR spectrophotometer Shimadzu 8400S; oily products were analyzed in the form of films, and solid compounds were analyzed as $\mathrm{KBr}$ pellets. The results of FT-IR spectroscopy were recorded as \% Transmittance vs. Wavenumber $\left(\mathrm{cm}^{-1}\right)$. ${ }^{1} \mathrm{H}$-NMR spectra $(500 \mathrm{MHz}$ ) were recorded using Bruker Advance spectrophotometer using TMS as an internal standard. Elemental analysis of the synthesized derivatives $(\mathrm{C}, \mathrm{H}, \mathrm{N}, \mathrm{O})$ were performed using Exeter CE-440 Elemental Analyzer and the results obtained were within $\pm 0.4 \%$ of the theoretical values. Mass spectra were obtained on a Hewlett Packard model GCD-1800A Electron Impact mass spectrometer at $70 \mathrm{eV}$ ionizing beam and using direct insertion probe.

\section{Reaction Scheme}

\section{Synthesis of nipecotic acid Prodrug}

N-Boc-Nipecotic Acid (Piperidine-1,3-dicarboxylic acid 1-tert-butyl ester) (2)

Synthesis of N-Boc nipecotic acid was according to the literature $[19,25]$ ( Fig. 4). Nipecotic acid (1) $1.0 \mathrm{gm}$ was dissolved in dioxane $(10.7 \mathrm{~mL})$ containing $\mathrm{NaOH}$ solution $(1 \mathrm{~N}, 9.6 \mathrm{ml})$ and stirred for $5 \mathrm{~h}$, with the addition of di-tert-butyl-dicarbonate $(1.9 \mathrm{~g})$. The solvent was evaporated, and the resulting aqueous mixture was separated with ethyl acetate $(15 \mathrm{~mL})$. Then, the $\mathrm{pH}$ of the resulting solution was brought down to 2.0 by the use of $1 \mathrm{~N} \mathrm{HCl}$ solution with vigorous stirring. The layers were separated, and the aqueous layer was extracted with EtOAc $(3 \times 10 \mathrm{~mL})$. The combined EtOAc extracts were dried over $\mathrm{Na}_{2} \mathrm{SO}_{4}$, filtered, and concentrated. Yield: $1.27 \mathrm{~g}, 71 \%$ as white solid: IR ( $\mathrm{KBr}, v_{\max } \mathrm{Cm}^{-1}$ ): 3450-3400 (-OH Str.), 2890 (C-H Str.), 1730 (C=O Str.), 1242 (C-O Str.), 1091 (C-O Str.), 935 (-OH Bend). ${ }^{1} \mathrm{H}$ NMR (500 $\mathrm{MHz}, \mathrm{CDCl} 3) \delta$ ppm: $\delta 10.63$ (s, 1H, -OH-carboxylic acid); 4.10-3.57 (m, 2H, 2-H), 3.34-3.10 (m, 2H, 6- H), 2.50-2.30(m, 1H, 3- H), 1.73$1.65(\mathrm{~m}, 2 \mathrm{H}, 4-\mathrm{H}), 1.50-1.45(\mathrm{~m}, 2 \mathrm{H}, 5-\mathrm{H}), 1.30-1.20$ (m, 9H, -Boc). MS (m/z): $230.11(\mathrm{M}+1)$; Anal. calc. for $\mathrm{C}_{11} \mathrm{H}_{19} \mathrm{NO}_{4}, \mathrm{C}, 57.62 ; \mathrm{H}, 8.35$; N, 6.11; O, 27.91; Found: C, 57.02; H, 8.01; N, 6.00; O, 27.32. 


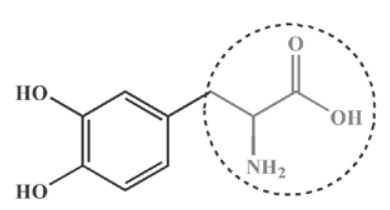

Levodopa (L-dopa)

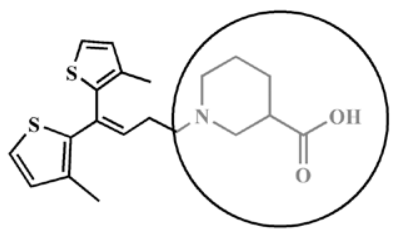

Tiagabine

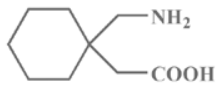

Gabapentine

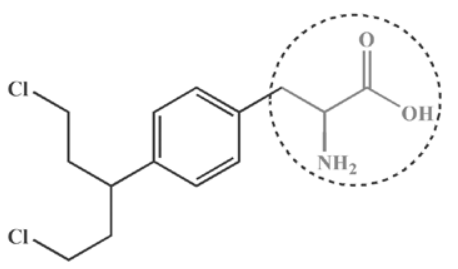

Melphalan

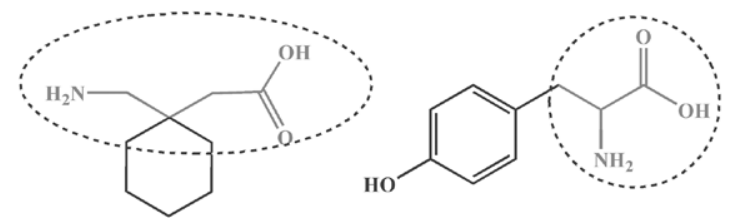

Tyrosine

Gabapentin

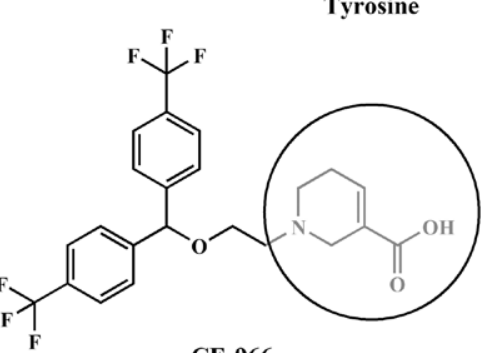

CE-966

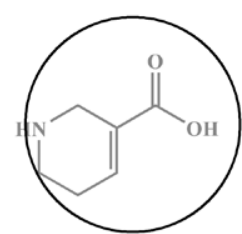

Guvacine

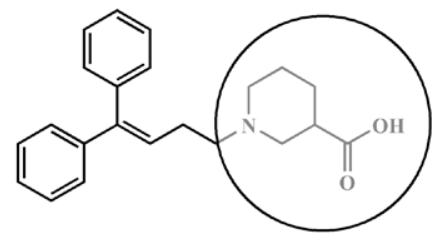

SKF89976A

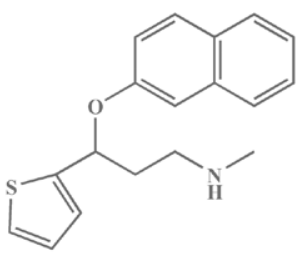

Duloxetine

Paroxetine

Leucine<smiles>CC(C)CC(N)C(=O)O</smiles>

Clom<smiles>CN(C)CCCN1c2ccccc2CCc2ccc(Cl)cc21</smiles>

mine

- Fig. 2 Existing LAT1 Substrates.

N-Boc-Nipecotic Acid N-Boc-L-Serine Ester (Piperidine-1,3dicarboxylic acid 3-(2-tert-butoxycarbonylamino-2carboxy-ethyl) ester 1-tert-butyl ester) (4)

Synthesis of compound (4) was according to the literature $[19,26]$

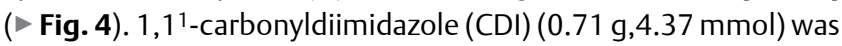
added to a solution of $\mathrm{N}$-Boc-Nipecotic Acid (1.0 g) in DCM/DMF $(3: 1,50 \mathrm{~mL})$, and the resulting mixture was stirred at RT. After the completion of the reaction, $\mathrm{N}$-Boc-L-Serine $(1.11 \mathrm{~g})$ in DCM/DMF $(3: 1,150 \mathrm{~mL})$ was added in a dropwise manner to the mixture over $120 \mathrm{~min}$, and stirring was then continued for $12 \mathrm{hrs}$. After evaporation of the solvent, the residue was taken up in EtOAc $(60 \mathrm{~mL})$ and washed with water $(2 \times 30 \mathrm{~mL})$. The organic layer was dried over $\mathrm{Na}_{2} \mathrm{SO}_{4}$ and evaporated. The crude compound was purified by column chromatography to afford the nipecotic acid prodrug as a paleyellow oil (1.33 g, 74\%).Yield: $1.33 \mathrm{~g}, 74 \%$ as white solid: IR $(\mathrm{KBr}$, $v_{\max } \mathrm{Cm}^{-1}$ ): 3350-3200 (-OH Str.), 2910 (C-H Str.), 1740 (C = O Str. ester), 1242 (C-O Str.), 1100 (C-O Str.), 950 (-OH Bend).1H NMR (500 MHz, CDCl3) $\delta$ ppm: $\delta 10.43$ (s, 1H, -OH-carboxylic acid); 7.91 (d, $1 \mathrm{H},-\mathrm{NH}$ sec amide), 4.90-4.45 (m, 1H, - $\mathrm{CH}) 4.10\left(\mathrm{~d}, 2 \mathrm{H},-\mathrm{CH}_{2}\right)$ 3.57-3.20 (m, 2H, 2-H), 3.12-2.90 (m, 2H, 6-H), 2.25-1.90 (m, $1 \mathrm{H}, 3-\mathrm{H}), 1.66-1.55(\mathrm{~m}, 2 \mathrm{H}, 4-\mathrm{H}), 1.40-1.35(\mathrm{~m}, 20 \mathrm{H}, 5-\mathrm{H}$ and -Boc). MS (m/z): $417.45(\mathrm{M}+1)$; Anal. calc. for $\mathrm{C}_{11} \mathrm{H}_{19} \mathrm{NO}_{4}, \mathrm{C}, 54.80$; $\mathrm{H}, 7.74$; N, 6.73; O, 30.73; Found: C, 54.34; H, 7.13; N, 6.32; O, 30.09 .
Nipecotic Acid L-Serine Ester (Piperidine-3-carboxylic acid 2-amino-2-carboxy-ethyl ester) (5)

Synthesis of compound (5) was according to the literature $[19,26,27]$ ( Fig. 4). To a solution of N-Boc-Nipecotic Acid N-BocL-Serine Ester $(1.75 \mathrm{~g})$ in DCM $(5 \mathrm{~mL})$, Trifluoroacetic acid (TFA) $(5 \mathrm{~mL})$ was added, and the mixture was stirred at RT for $2 \mathrm{~h}$. Evaporation of the solvent gave a residue that was taken up in water $(20 \mathrm{~mL})$, neutralized with $10 \%$ aqueous $\mathrm{NH}_{4} \mathrm{OH}$, diluted with more water, and washed with $\mathrm{CHCl}_{3}(3 \times 15 \mathrm{~mL})$. The aqueous layers were concentrated in vacuo, and the crude was submitted to cation-exchange chromatography, eluting with $10 \%$ pyridine in water to give the final product. $620 \mathrm{mg}$ of 6 ( $68 \%$ yield) as a white solid. Yield: $620 \mathrm{mg}, 68 \%$ as white solid: IR $\left(\mathrm{KBr}, v_{\max } \mathrm{cm}^{-1}\right)$ : $3410-3090(-\mathrm{OH}$ Str\&-NH /-NH 2) $^{-} 2910$ (C-H Str.), 1720 (C = O Str. ester), 1250 (C-O Str.), 1100 (C-O Str.), 950 (-OH Bend). ${ }^{1} \mathrm{H}$ NMR (500 MHz, CDCl3) $\delta$ ppm: $\delta 10.80$ (s, 1H, -OH-carboxylic acid), 4.70-4.65 (m, 1H, -CH) $4.10\left(\mathrm{~d}, 2 \mathrm{H},-\mathrm{CH}_{2}\right) 3.45-3.30(\mathrm{~m}, 2 \mathrm{H}, 2-\mathrm{H}), 3.12-3.05(\mathrm{~m}, 2 \mathrm{H}$, 6-H), 2.30-2.20 (m, 3H, $-\mathrm{NH}$ and $\left.\mathrm{NH}_{2}\right), 2.15(\mathrm{~m}, 1 \mathrm{H}, 3-\mathrm{H}), 1.70(\mathrm{~m}$, $2 \mathrm{H}, 4-\mathrm{H}), 1.39$ (m, 2H, 5-H). MS (m/z): $217.45(\mathrm{M}+1)$; Anal. calc. for $\mathrm{C}_{11} \mathrm{H}_{19} \mathrm{NO}_{4}, \mathrm{C}, 49.99 ; \mathrm{H}, 7.46 ; \mathrm{N}, 12.96$; O, 29.60; Found: $\mathrm{C}$, 48.66; H, 7.10; N, 12.22; O, 29.76. 


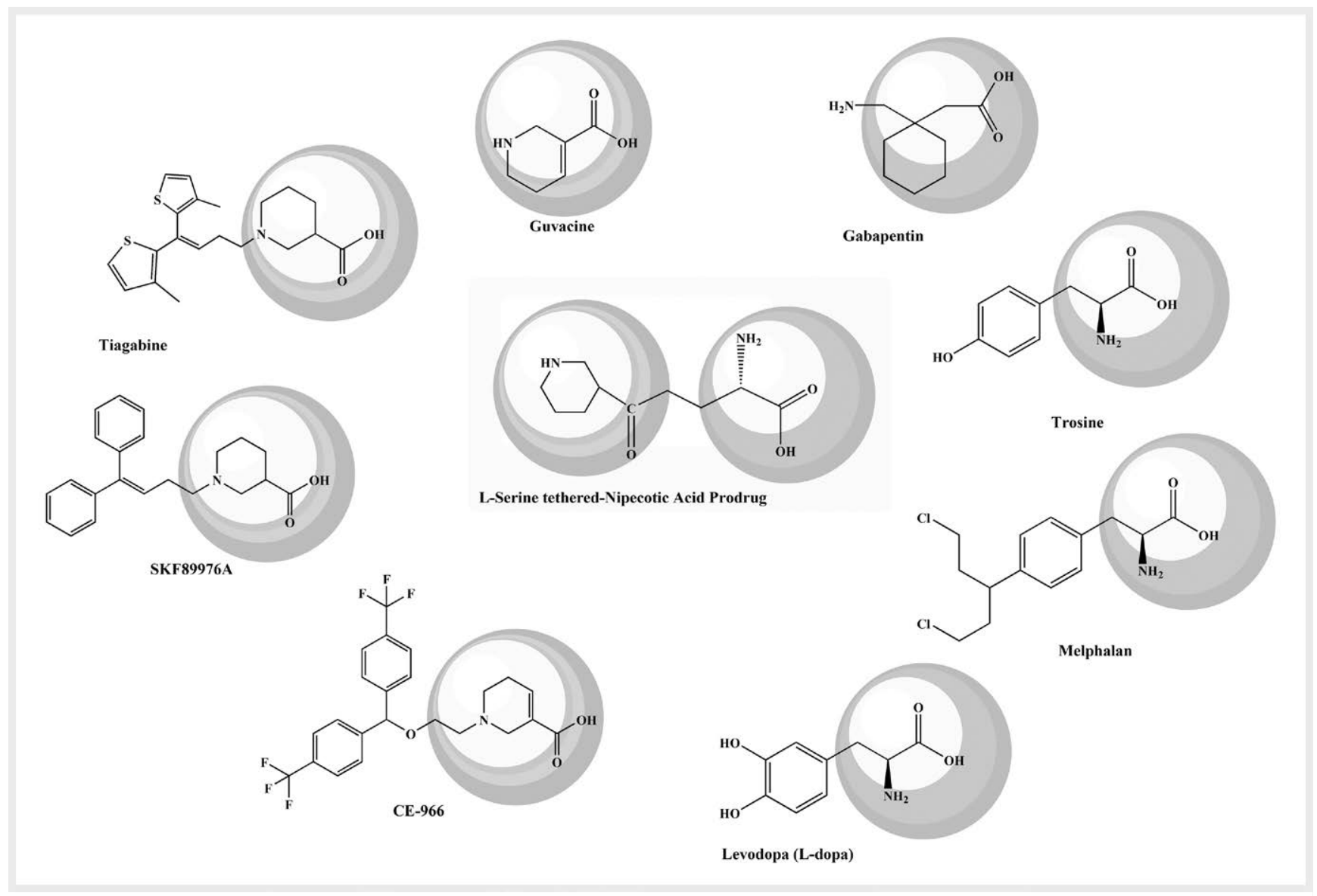

- Fig. 3 Design strategy using molecular hybridization approach via tethering L-Serine with nipecotic acid.<smiles>O=C(O)C1CCCNC1</smiles><smiles>O=C(O)C1CCCN(CCCCO)C1</smiles><smiles>O=C(O)[C@@H](CO)NCCO</smiles><smiles>N[C@@H](COC(=O)C1CCCNC1)C(=O)O</smiles>

5

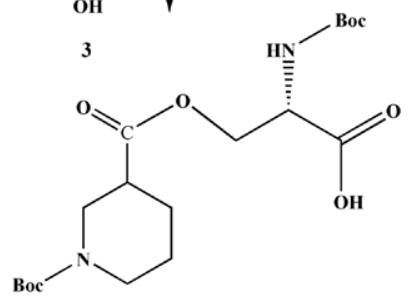

- Fig. 4 Schematic representation for the synthesis of Nipecotic acid Prodrug. 

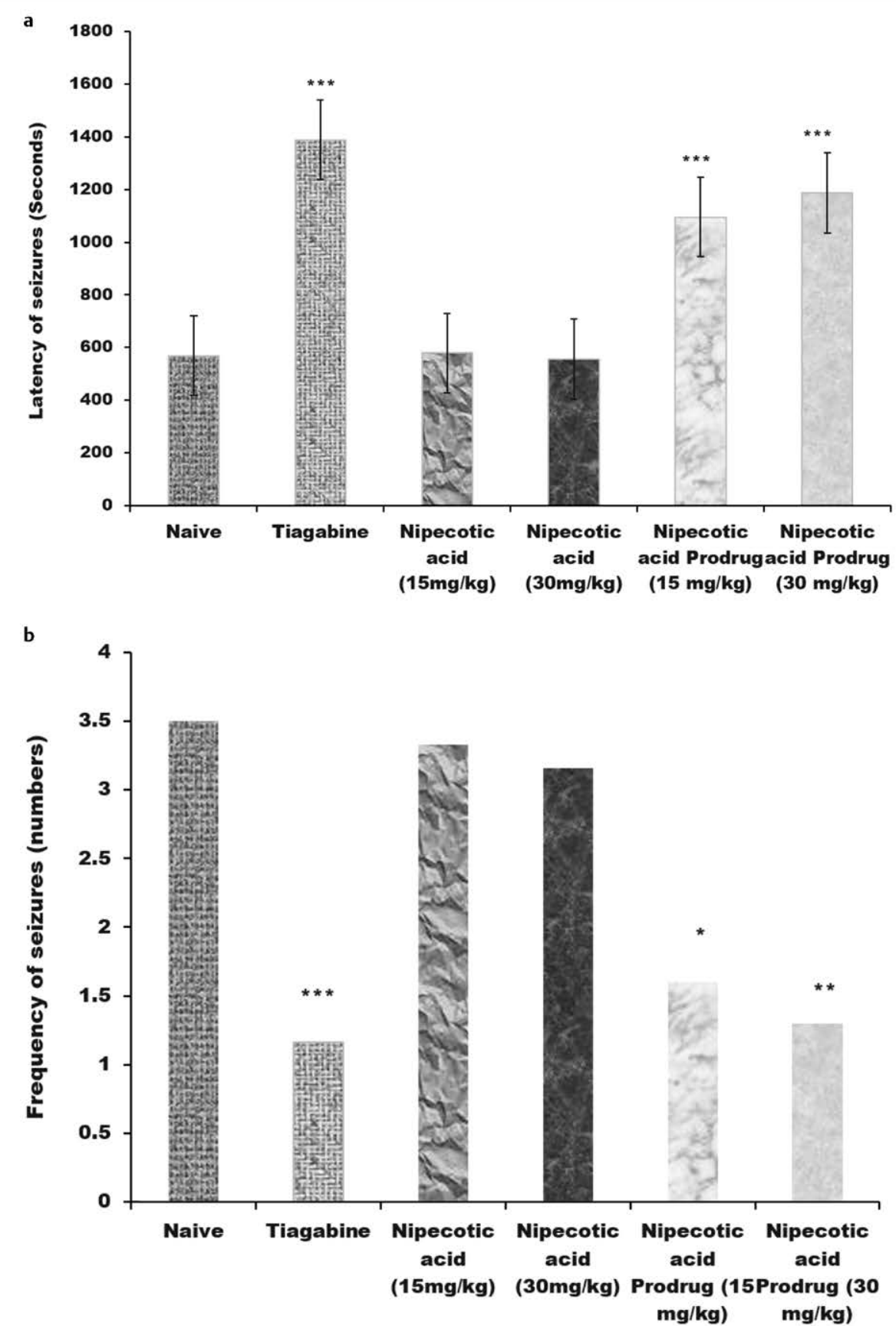

> Fig. 5 a Effect of drugs on s.c. administered PTZ induced seizures-Latency of seizures; b Effect of drugs on s.c. administered PTZ induced seizuresFrequency of seizures.

\section{Pharmacology}

\section{Animals}

Swiss albino male mice (25-30 g body weight) were procured from the animal house, MM College of Pharmacy, MM (Deemed to be University), Mullana, Ambala, Haryana. The animals were housed in groups of six in polypropylene cages at an ambient temperature of $25 \pm 1^{\circ} \mathrm{C}$ and $45-55 \%$ relative humidity, with a $12: 12 \mathrm{~h}$ light/dark cycle. Animals were provided with commercial food pellets and water ad libitum unless stated otherwise. Animals were acclimatized to laboratory conditions for at least one week before using them for experiments. Body weight of animals was measured periodically. Principles of laboratory animal care guidelines (NIH publication number 85-23, revised 1985) were followed. Protocols of the study were approved by Institutional Animal Ethical Committee of MM College of Pharmacy, MM (Deemed to be University), Mullana, Ambala, Haryana. The Approval number is MMCPIAEC-60-1. 


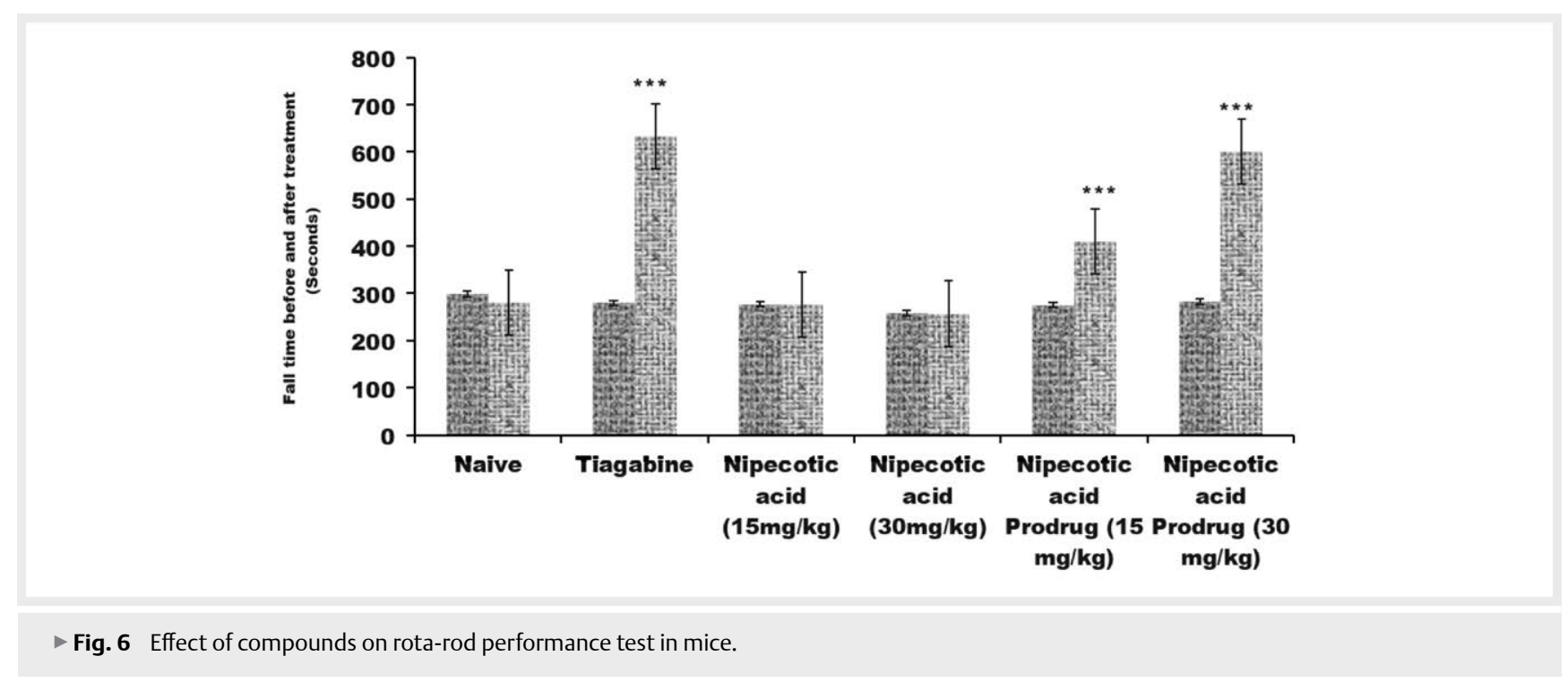

\section{Preclinical Studies}

Pentylenetetrazole (PTZ)-Induced Convulsions in Mice

In this test, rodents were challenged a subcutaneous dose of PTZ, one hour after the administration of test compounds and the standard drug and were observed for 30 mins. It has been reported that a subcutaneously injected convulsive dose of PTZ induces a clonic seizure of at least 5 sec duration in $97 \%$ of the animals (CD97) [28, 29].

In any experimental session a maximum of 6 animals were acutely injected i.p. with saline (control), nipecotic acid, nipecotic acid prodrug (L-serine ester) and tiagabine (standard). Twenty-five mins after the treatment, all mice were s.c. injected with PTZ and the animals were observed for the following $30 \mathrm{~min}$. The latency of convulsions (in secs) and lethality were measured to evaluate the effects of the treatments on PTZ-induced convulsions.

Lethality was defined as the percentage of the animal died within 60 min after PTZ injection. The onset times were recorded as secs. Loss of righting reflex preceded by clonus of the whole body lasting more than $3 \mathrm{sec}$ was considered as clonic seizures. Latency to first seizure ( $\vee$ Fig. $\mathbf{5 a}$ ) and number of seizures $(\triangleright \mathbf{F i g} . \mathbf{5 b}$ ) were noted and compared to control group [physiological saline (0.9\%) containing $2.5 \%$ tween]. No lethality was observed in any of the groups.

Test compounds were administered intraperitoneally, one hour before PTZ challenge [27]. The PTZ (Sigma Aldrich) was administered to mice s.c. at the dose of $100 \mathrm{mg} / \mathrm{kg}$.

Among different treatments in anticonvulsant activity, nipecotic acid prodrug at both the doses $(15 \mathrm{mg} / \mathrm{kg}$ and $30 \mathrm{mg} / \mathrm{kg}$ ) exhibited an extremely statistically significant $(p<0.001)$ delay in the onset of convulsion similar to tiagabine in comparison to naïve control group. Whereas, frequency of seizures also reduced with nipecotic acid prodrug at both doses and showed dose dependent effect when compared to naïve control group.

\section{Rota-Rod Performance Test in Mice}

The rota-rod test is widely used to evaluate the effect of compounds on the motor coordination of rodents [30]. Only those mice that stayed for more than 3 mins on rotating rod $(10 \mathrm{rpm}$ ) were selected for the test procedure. The test session was performed on the same day as the pre-test session. Fall-off time (when the rat falls from the rotating rod) for each animal was noted before and after dosing [31].

The test compounds and tiagabine were administered $1 \mathrm{hr}$ before test session, respectively. In this experiment, nipecotic acid prodrug at both the doses and tiagabine showed extremely statistically significant $(p<0.001)$ results when compared to nipecotic acid and naïve control group ( $\vee$ Fig. 6 ). This reveals that both of them (nipecotic acid prodrug and tiagabine) did not cause any alteration in "fall-off" time on rotating rods as compared to control indicating their inability to induce any observable signs of impairment in muscle co-ordination thereby affecting the motor performance and skeletal, muscular strength of the treated animals.

\section{Analgesic activity in mice}

Acetic acid writhing test: Acetic acid-induced writhing test was performed as reported elsewhere in literature [32]. Mice were treated with nipecotic acid, tiagabine and nipecotic acid-prodrug at both drug levels and the saline 30 min before i.p. injection of $0.6 \%$, $10 \mathrm{~mL} / \mathrm{kg}$ body weight acetic acid. The study is basically to count the number of writhes (abdominal constrictions) which starts from 5 min after the injection of acetic acid up to 20 mins for each group of mice and are expressed as percent protection.

Tail-suspension test: to study the depressive behaviour the procedure was adopted from the literature with slight modifications $[33,34]$. The method is based on the observation that a mouse suspended by its tail shows alternate period of activity and immobility. Each mouse was suspended above the floor by approximately $1 \mathrm{~cm}$ from the tip of the tail via a thread. The thread was moved from a pulley, and its other end was attached to a force transducer connected to a student physiograph (Biodevices, Ambala, India) adjusted to a speed of $0.5 \mathrm{~mm} / \mathrm{s}$ to record the exact immobility period (secs). Immobility time was recorded for 6 min. 

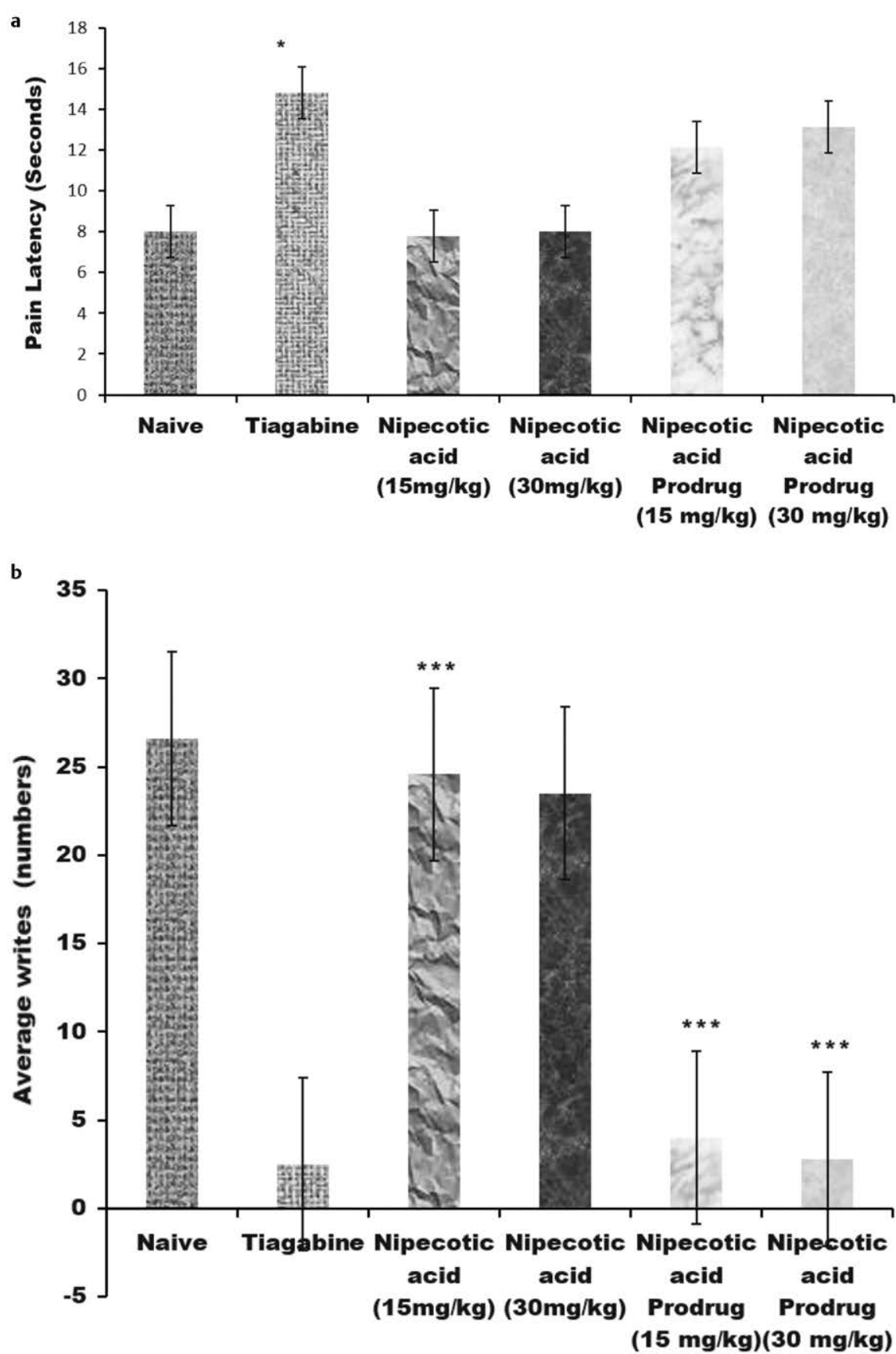

Fig. 7 a Effect of compounds on Analgesic activity in mice- Pain latency (Tail-suspension test); b Effect of compounds on Analgesic activity in mice-Average Writhes (Acetic acid writhing test).

In threshold pain parameter (Tail-suspension test), only tiagabine treatment group showed slightly significant effect $(p<0.05)$ when compared to naïve control group ( $>$ Fig. $7 a)$. Whereas, writhing movement were noticed after treatment and found to be reduced in both the nipecotic acid prodrug groups. In this study the results were statistically significant $(p<0.001)$ when compared to naïve control group ( $\vee$ Fig. 7b).
HPLC analysis: Determination of nipecotic acid in mouse brain

The HPLC system comprised of 515 binary pumps (Waters, USA), a multi-wavelength fluorescence detector and Rheodyne manual injector with $20-\mu \mathrm{L}$ injection volume. Flow rate was kept at $1 \mathrm{~mL} / \mathrm{min}$. The chromatographic separation was achieved on a reverse-phase analytical column (150 mm × $4.6 \mathrm{~mm}, 5 \mu \mathrm{m}$; Agilent, USA).

Mice were treated with saline, tiagabine, nipecotic acid $(15 \mathrm{mg} / \mathrm{kg}$ and $30 \mathrm{mg} / \mathrm{kg}$ ) and nipecotic acid prodrug ( $15 \mathrm{mg} / \mathrm{kg}$ and $30 \mathrm{mg} / \mathrm{kg})$. 
- Table 1 HPLC analysis: Determination of nipecotic acid in mouse brains.

\begin{tabular}{|l|l|}
\hline Sample for treatment & Nipecotic Acid $\mathbf{n m o l} / \mathbf{g}^{\mathbf{x}}$ \\
\hline Control (Saline) & No drug \\
\hline Tiagabine & 650 \\
\hline Nipecotic acid $(15 \mathrm{mg} / \mathrm{kg})$ & No drug \\
\hline Nipecotic acid $(30 \mathrm{mg} / \mathrm{kg})$ & 90 \\
\hline Nipecotic acid prodrug $(15 \mathrm{mg} / \mathrm{kg})$ & 450 \\
\hline Nipecotic acid prodrug $(30 \mathrm{mg} / \mathrm{kg})$ & 610 \\
\hline $\begin{array}{l}\text { Nipecotic acid concentration in mice brain, } 30 \text { mins after injection of } \\
\text { saline, } \text { ximit of quantification }(\mathrm{LOQ}) \text { of nipecotic acid was } \sim 61 \mathrm{nmol} / \mathrm{g}\end{array}$ \\
\hline
\end{tabular}

They were anesthetized and sacrificed by decapitation 30 min after injection. The brains were processed and the filtrates were derivatized as described in the literature [35]. The amount of nipecotic acid in brain was calculated with the brain standard curves, from the average AUC values for three triplicates for each brain supernatant. The samples were analysed at a wavelength of $284 \mathrm{~nm}$ by using an UV/Vis variable wavelength detector. The results were shown in $>$ Table 1.

\section{Statistical analysis}

The data presented in the tables/figures are the mean \pm standard deviation (SD). The statistical difference between mean was analysed using ANOVA and by Tukey's multiple comparison test. The $P$ value less than 0.05 was considered as significant

\section{Result and Discussion}

\section{Chemistry}

At the outset, either the commercially available Boc protected nipecotic acid and L-serine were used or were synthesized as per reported procedure $[19,25]$. Further, the building of crucial intermediate ester conjugate of N-Boc-nipecotic acid and N-Boc-L-serine was achieved by the esterification as described in literature [19]. The nipecotic acid prodrug was prepared by the deprotection of Boc with the appropriate reagent trifluoroacetic acid $[19,26]$ and [27] (॰ Fig. 4).

The FT-IR spectra of the compound $\mathbf{4}$ and $\mathbf{5}$ exhibited the characteristic medium $\mathrm{C}=\mathrm{O}$ stretching of ester peak in the range of 1690-1750 cm-1 (C = O Str. ester), The ${ }^{1} \mathrm{H}$ NMR of compounds 4 and 5 showed a carboxyl peak of the acid at down field (11.00$10.80 \delta$ value), 8.10 (d, $1 \mathrm{H},-\mathrm{NH}$ sec amide), 4.90-4.45 (m, $1 \mathrm{H},-\mathrm{CH})$ $4.10\left(\mathrm{~d}, 2 \mathrm{H},-\mathrm{CH}_{2}\right) 3.57(\mathrm{~m}, 2 \mathrm{H}, 2-\mathrm{H}), 3.12(\mathrm{~m}, 2 \mathrm{H}, 6-\mathrm{H}), 2.25(\mathrm{~m}$, $1 \mathrm{H}, 3-\mathrm{H}), 1.66(\mathrm{~m}, 2 \mathrm{H}, 4-\mathrm{H}), 1.40$ (m, 20H, 5-H and -Boc).

Whereas the nipecotic acid prodrug shows multiple peaks for free $\mathrm{NH}$ group at $\delta 2.30\left(\mathrm{~m}, 3 \mathrm{H}\right.$, - $\mathrm{NH}$ and $\left.\mathrm{NH}_{2}\right)$. The protons of methylene bridge $(-\mathrm{CH} 2)$ were observed as doublet peak in the range of 4.10-3.80 ppm. Elemental analysis of all the compounds are in accordance with expected values.

\section{Pharmacology}

\section{Antiepileptic activity}

The synthesized nipecotic acid prodrug was subjected to evaluation of antiepileptic activity in PTZ-induced models of epilepsy in rodents.
The role of the GABAergic system in the genesis of epilepsy is well documented and understood. The imbalance in the inhibitory and excitatory pathways is mediated by GABA complex, triggered by chemical or electrical impulses leading to the generation of seizures. As a consequence, any drug supporting the inhibitory function of GABA directly or indirectly has the potential to suppress epilepsy and associated phenomena. Tiagabine, a derivative of nipecotic acid is one of these kinds of drug. Tiagabine reduces neuronal excitability by inhibiting GABA uptake into glia and neurons. It increases synaptosomal concentrations of the inhibitory neurotransmitter GABA via inhibition of the GABA transporter GAT-1 $[2,36,37]$.

In this test, rodents were challenged a subcutaneous dose of PTZ, one hour after the administration of test compounds and the standard drug and were observed for 30 mins. Nipecotic acid prodrug exhibited a significant delay in the onset of convulsion similar to tiagabine in comparison to control group. These results can support that the synthesized title compound (nipecotic acid prodrug) has the ability to significantly cross the BBB and to increase the level of GABA in a manner similar to tiagabine.

\section{Rota-rod performance test in mice}

The rota-rod test is widely used to evaluate the effect of compounds on the motor coordination of rodents [30]. In this experiment the synthesized Nipecotic acid Prodrug and tiagabine did not cause any alteration in "fall-off" time on rotating rods as compared to control indicating their inability to induce any observable signs of impairment in muscle co-ordination thereby affecting the motor performance and skeletal, muscular strength of the treated animals. Standard drug diazepam was however seen to significantly reduce the "falloff" time post-treatment.

\section{Analgesic activity in mice}

It was observed that, only tiagabine presented significant effect as compared to naïve control group in the pain threshold studies whereas, writhing movements were noticed after treatment and found to be reduced in both the nipecotic acid prodrug groups. In this study the results were statistically significant $(p<0.001)$ when compared to naïve control group

\section{HPLC}

To prove that the synthesized compound can cross the BBB, nipecotic acid concentration in mouse brains was evaluated. The mice were treated with saline solution, tiagabine, nipecotic acid and nipecotic acid prodrug. Thirty mins after injection the mice were sacrificed and nipecotic acid concentration in brain was determined by HPLC analysis. The saline treated group did not show any traces of nipecotic acid in the brain, nor did the nipecotic treated group, whereas, the mice treated with nipecotic acid Prodrug with $30 \mathrm{mg} / \mathrm{kg}$ dose level showed $610 \mathrm{nmol} / \mathrm{g}$ concentration of nipecotic acid in the brain which in contrast to that of the concentration of Tiagabine.

\section{Conclusions}

The approach of transport of drugs through BBB by means of endogenous transporters is of phenomenal importance ad has already 
been proven process which we have used in this work. All the analytical studies were done to confirm the structural aspects of the nipecotic acid prodrug along with various pharmacological studies, which were conducted to justify the claimed aspects of the design and effectiveness of the prodrug. The results obtained are in accordance with that were initially assumed. The nipecotic acid prodrug greatly enhances the transport of nipecotic acid through BBB justifying the rationale of design. We are further exploring this possibility with other active molecules endowed with poor or no BBB-crossing properties.

\section{Funding}

The authors want to thank to MM College of Pharmacy, MM (Deemed to be University), for all the financial supports for the work.

\section{Conflict of Interest}

The authors declare no conflict of interest, financial or otherwise

\section{References}

[1] Davies JA. Mechanisms of action of antiepileptic drugs. Seizure Eur J Epilepsy 1995; 4: 267-271

[2] Löscher W, Schmidt D. New horizons in the development of antiepileptic drugs: Innovative strategies. In: Epilepsy Research 2006; 69: $183-272$

[3] Abou-Khalil BW. Update on Antiepileptic Drugs 2019. Contin Lifelong Learn Neurol 2019; 25: 508-536

[4] Eulenburg V, Gomeza J. Neurotransmitter transporters expressed in glial cells as regulators of synapse function. Brain Res Rev 2010; 63: 103-112

[5] Oakley JC, Cho AR, Cheah CS et al. Synergistic GABA-enhancing therapy against seizures in a mouse model of dravet syndrome. J Pharmacol Exp Ther 2013; 345: 215-224

[6] Yunger LM, Fowler PJ, Zarevics P et al. Novel inhibitors of $\gamma$-aminobutyric acid (GABA) uptake: Anticonvulsant actions in rats and mice. J Pharmacol Exp Ther 1984; 228: 109-115

[7] Schousboe A, Madsen KK, Barker-Haliski ML et al. The GABA Synapse as a Target for Antiepileptic Drugs: A Historical Overview Focused on GABA Transporters. Neurochem Res 2014; 39: 1980-1987

[8] Ali FE, Bondinell WE, Dandridge PA et al. Orally Active and Potent Inhibitors of $\mathrm{Y}$-Aminobutyric Acid Uptake. J Med Chem 1985; 28 : 653-660

[9] Shimizu K, Ohtaki K, Matsubara K et al. Carrier-mediated processes in blood-brain barrier penetration and neural uptake of paraquat. Brain Res 2001; 906: 135-142

[10] Nielsen EB, Suzdak PD, Andersen KE et al. Characterization of tiagabine (NO-328), a new potent and selective GABA uptake inhibitor. Eur J Pharmacol 1991; 196: 257-266

[11] Bjorge S, Black A, Bockbrader $\mathrm{H}$ et al. Synthesis and metabolic profile of Cl-966: A potent, orally-active inhibitor of GABA uptake. Drug Dev Re 1990; 21: 189-193

[12] Taylor CP, Vartanian MG, Schwarz RD et al. Pharmacology of Cl-966: A potent GABA uptake inhibitor, in vitro and in experimental animals. Drug Dev Res 1990; 21: 195-215
[13] Falch E, Krogsgaard-Larsen P. Gaba uptake inhibitors containing mono- and diarylmethoxyalkyl N-substituents. Drug Des Deliv 1989; 4: $205-215$

[14] Pardridge WM, Oldendorf WH. Kinetic analysis of blood-brain barrier transport of amino acids. BBA - Biomembr 1989; 4: 205-215

[15] Boado RJ, Li JY, Nagaya M et al. Selective expression of the large neutral amino acid transporter at the blood-brain barrier. Proc Natl Acad Sci U S A 1999; 96: 12079-12084

[16] Löscher W. Anticonvulsant action in the epileptic gerbil of novel inhibitors of GABA uptake. Eur J Pharmacol 1985; 110: 103-108

[17] Killian DM, Hermeling S, Chikhale PJ. Targeting the cerebrovascular large neutral amino acid transporter (LAT1) isoform using a novel disulfide-based brain drug delivery system. Drug Deliv 2007; 14: 25-31

[18] Walker I, Nicholls D, Irwin WJ et al. Drug delivery via active transport at the blood-brain barrier: affinity of a prodrug of phosphonoformate for the large amino acid transporter. Int J Pharm 1994; 104: 157-167

[19] Bonina FP, Arenare L, Palagiano F et al. Synthesis, stability, and pharmacological evaluation of nipecotic acid prodrugs. J Pharm Sci 1999; 88: 561-567

[20] Gynther M, Laine K, Ropponen J et al. Large neutral amino acid transporter enables brain drug delivery via prodrugs. J Med Chem 2008; 51: 932-936

[21] Puris E, Gynther M, Huttunen J et al. L-type amino acid transporter 1 utilizing prodrugs: How to achieve effective brain delivery and low systemic exposure of drugs. J Control Release 2017; 261: 93-104

[22] Peura L, Malmioja K, Laine K et al. Large amino acid transporter 1 (LAT1) prodrugs of valproic acid: New prodrug design ideas for central nervous system delivery. Mol Pharm 2011; 8: 1857-1866

[23] Peura L, Malmioja K, Huttunen K et al. Design, synthesis and brain uptake of lat1-targeted amino acid prodrugs of dopamine. Pharm Res 2013; 2523-2537

[24] Ylikangas H, Malmioja K, Peura L et al. Quantitative insight into the design of compounds recognized by the L-type amino acid transporter 1 (LAT1). Chem. Med Chem 2014; 9: 2699-2707

[25] Kim YC, Zhao LX, Kim TH et al. Design and synthesis of anticonvulsive agents as $\gamma$-vinyl GABA-based potential dual acting prodrugs and their biological activities. Bioorganic Med Chem Lett 2000; 10: 609-613

[26] Napolitano C, Scaglianti M, Scalambra E et al. Carnitine Conjugate of Nipecotic acid: A new example of dual prodrug. Molecules 2009; 14: 3268-3274

[27] Seth A, Sharma PA, Tripathi A et al. Design, Synthesis, Evaluation and Computational Studies of Nipecotic Acid-Acetonaphthone Hybrids as Potential Antiepileptic Agents. Med Chem (Los Angeles) 2018; 14: 409-426

[28] Löscher W. Critical review of current animal models of seizures and epilepsy used in the discovery and development of new antiepileptic drugs. Seizure 2011; 20: 359-368

[29] Kowalczyk P, Sałat K, Höfner GC et al. Synthesis, biological evaluation and structure-activity relationship of new GABA uptake inhibitors, derivatives of 4-aminobutanamides. Eur J Med Chem 2014; 83: 256-273

[30] Shiotsuki $\mathrm{H}$, Yoshimi $\mathrm{K}$, Shimo $\mathrm{Y}$ et al. A rotarod test for evaluation of motor skill learning. J Neurosci Methods 2010; 189: 180-185

[31] Kulkarni SK, Joseph P. Psychopharmacological profile of siotone granules ${ }^{\circledR}$, a herbal preparation. Indian Drugs 1998; 35: 536-554

[32] Aydin S, Demir T, Öztürk Y et al. Analgesic activity of Nepeta italica L. Phyther Res 1999; 13: 20-23

[33] Steru L, Chermat R, Thierry B et al. The tail suspension test: a new method for screening antidepressants in mice. Psychopharmacology (Berl) 1985; 85: 367-370 
[34] Singh D, Mishra A, Goel RK. Effect of saponin fraction from Ficus religiosa on memory deficit, and behavioral and biochemical impairments in pentylenetetrazol kindled mice. Epilepsy Behav 2013; 27: 206-211

[35] Nassereddine-Sebaei M, Crider AM, Carroll RT et al. Determination of $\mathrm{m}$-nitrophenol and nipecotic acid in mouse tissues by high-performance liquid chromatography after administration of the anticonvulsant m-nitrophenyl-3-piperidinecarboxylate hydrochloride. J Pharm Sci 1993; 82: 39-43
[36] Bauer ], Cooper-Mahkorn D. Tiagabine: Efficacy and safety in partial seizures - Current status. Neuropsychiatr Dis Treat 2008; 4: 731-736

[37] De Deyn PP, D'Hooge R, Marescau B et al. Chemical models of epilepsy with some reference to their applicability in the development of anticonvulsants. Epilepsy Res 1992; 1992: 87-110 